\title{
James Gordon Gray, D.Sc., M.I.E.E.
}

PROFESSOR GRAY died suddenly at his home at Dowanhill on Tuesday, November 6, 1934. From the beginning of the session he had been absent intermittently, but he had delivered two lectures on the previous Monday, and his death came as a great shock to everyone.

Professor Gray was born in Glasgow in 1876 . He was the second son of the late Professor Andrew Gray, F.R.S., and was educated at Bangor where his father was Professor of Physics. But when his father was appointed to the Chair of Natural Philosophy in the University of Glasgow in I899, Gray entered as a student at Glasgow, and took the B.Sc. course in electrical engineering. In 1904 he was appointed to his father's staff as assistant, in 1908 he became senior lecturer in the department, and in 1920 he was appointed to the new Chair of Applied Physics founded by Sir John Cargill for the teaching of physics to students of medicine and engineering. In I9I I appeared the Treatise on Dynamics, written in collaboration with his father, which is well known as a textbook for University students.

His first scientific investigations were on magnetism, for which he obtained the D.Sc. degree in 1908; some of these are described in the Society's Proceedings. In this work he was associated with A. D. Ross, who afterwards became Professor of Mathematics and Physics in the newly founded University of West Australia. In 1910, at his father's suggestion, he took up the study of gyrostats, a subject which had been associated with the department since the time of Lord Kelvin, and this became his life-work. At first he contented himself with constructing models for demonstrating the properties of gyrostats, walking and climbing gyrostats, gyrostatic bicycles and tricycles, pole-balancing tops, etc., but later proceeded on to original devices, and during the War achieved his greatest success, the gyrostatic stabiliser. This provided a platform for use in aeroplanes, amongst other purposes, which remained absolutely steady no matter how the aeroplane rocked, and from which bombs could be dropped with very much greater accuracy than from an ordinary aeroplane.

He gave frequent demonstrations of his inventions before the Royal Societies of London and Edinburgh and other scientific bodies, and he was in great request as a lecturer on the subject, being celebrated as an authority on gyrostats both in this country and in America. 
As a teacher he was clear and painstaking. He retained throughout life an ability to see matters from the students' point of view, and he had a gift of humour which endeared him to the weaker members of the class. He inherited from his father a strong fund of common sense, and from him gained a knowledge of University affairs which made his judgment very reliable. His death breaks a direct connection of thirty-five years with the University of Glasgow, and severs a link, through his father, with the classic days of Lord Kelvin's laboratory.

He was elected a Fellow of the Society in 1909.

R. A. H. 